\title{
Biofilm dispersal for spore release in Bacillus subtilis
}

\author{
Kovács, Ákos T.; Stanley-Wall, Nicola R.
}

Published in:

Journal of Bacteriology

Link to article, DOI:

10.1128/JB.00192-21

Publication date:

2021

Document Version

Peer reviewed version

Link back to DTU Orbit

Citation (APA):

Kovács, Á. T., \& Stanley-Wall, N. R. (2021). Biofilm dispersal for spore release in Bacillus subtilis. Journal of Bacteriology, 23(14), [e00192-21]. https://doi.org/10.1128/JB.00192-21

\section{General rights}

Copyright and moral rights for the publications made accessible in the public portal are retained by the authors and/or other copyright owners and it is a condition of accessing publications that users recognise and abide by the legal requirements associated with these rights.

- Users may download and print one copy of any publication from the public portal for the purpose of private study or research.

- You may not further distribute the material or use it for any profit-making activity or commercial gain

- You may freely distribute the URL identifying the publication in the public portal

If you believe that this document breaches copyright please contact us providing details, and we will remove access to the work immediately and investigate your claim 
1 Biofilm dispersal for spore release in Bacillus subtilis

2

3 Ákos T. Kovács ${ }^{1}$, Nicola R. Stanley-Wall ${ }^{2}$

4

$5{ }^{1}$ Bacterial Interactions and Evolution Group, DTU Bioengineering, Technical University of

6 Denmark, Kongens Lyngby, Denmark

$7 \quad{ }^{2}$ Division of Molecular Microbiology, School of Life Sciences, University of Dundee, Dundee, UK

8

$9 \quad$ Address correspondence to Ákos T. Kovács, atkovacs@dtu.dk

10

\section{ABSTRACT}

12 The dispersal of bacterial cells from a matured biofilm can be mediated either by active or passive

13 mechanisms. In this issue of the Journal of Bacteriology, Nishikawa and Kobayashi demonstrate

14 that the presence of calcium influences dispersal of spores from the pellicle biofilm of Bacillus

15 subtilis. The authors propose that temporal heterogeneity in matrix production and chelation of

16 calcium by dipicolinic acid in spores weakens the biofilm matrix and causes passive dispersal.

18 KEYWORDS

19 Bacillus subtilis, biofilm, dispersal, spore, development

COMMENTARY

22 Biofilm formation is a complex developmental process undertaken by microbes that is initiated by

23 attachment or aggregation of cells, advanced by production of an extracellular matrix, and 
24 generally finalized by disassembly of the biofilm, a process called dispersal (1). The specific biofilm 25 life cycle depends on the microorganism, its ecological niche, and the encoded regulatory pathways. In addition, environmental factors, including intra- and interspecies compounds may influence the different steps of biofilm development. A detailed understanding of the different stages of biofilm formation and disassembly could help us to prevent deleterious microbial communities and promote beneficial ones.

Bacillus subtilis became a model organism to study bacterial differentiation processes due to its ability to create a dormant cell structure, called a spore, that has remarkably resistance to heat, pressure, and chemicals in addition to its capability to take up extracellular DNA and incorporate it via recombination into its genome (2). These features, alongside other biotechnologically beneficial properties stimulated robust probing of the physiology and genetics of this species in the last century. The study of $B$. subtilis biofilm formation was initiated about two decades ago, and has created a plethora of understanding since the first publication (3) regarding how gene expression connects to biofilm initiation and matrix production and the identity and function of the main biofilm matrix components $(4,5)$. Interest in $B$. subtilis biofilms is further stimulated by 39 the species being more than a laboratory model: biofilms are important for plant growth 40 promotion, probiotic impact, and biotechnological applications $(6,7)$.

41 The molecular details of $B$. subtilis biofilm development have been predominantly explored in two 42 laboratory systems, air-liquid interface floating biofilms, known as pellicles, and architecturally 43 complex colonies formed on agar surface (6). Dissection of gene expression in colonies revealed that $B$. subtilis biofilm population is phenotypically heterogeneous; distinct cell types inhabit a

45 biofilm, including motile cells, matrix producers, extracellular protease producers, and in the later stages of development, spores are formed on the upper layer of the colonies (8, 9). Efficient 
47 initiation of pellicle development requires motility (10) and establishment of the floating biofilm at 48 the air-medium interface proceeds through distinct morphological changes (11). Importantly, 49 matrix gene expression in the nascent pellicle is temporally and spatially heterogeneous, after a 50 highly heterogeneous matrix production during initiation of the pellicle, the majority of cells 51 express the genes for matrix production in the middle of biofilm development (around 24 hours) 52 (12). In the later stages, the population becomes heterogeneous again, only a fraction of the cells 53 will produce the matrix (12), while spores also appear $(13,14)$. Such temporal heterogeneity is 54 mirrored by physical heterogeneity; during the initial and later stages of pellicle development, 55 next to a robust, highly matrix-expressing population, a fragile fraction is also present, within 56 which the cell-cell aggregation can be easily disrupted (12). The dynamic transcriptional landscape 57 of the developing pellicle has also been associated with variation in metabolism of the cells (15). 58 Additionally, it has been proposed that during biofilm colony maturation, the evolutionary 59 younger and more diverged genes are increasingly expressed toward later timepoints of colony 60 development (16).

61 While initiation and maturation of pellicle biofilm development is extensively investigated, 62 dispersal mechanisms are less explored in B. subtilis and the literature still perpetuates errors in 63 the understanding of biofilm dispersal with respect to norspermidine and D-amino acids that have 64 since been corrected $(17,18)$. In this issue of Journal of Bacteriology, the publication by Nishikawa 65 and Kobayashi (19) reveals a novel mechanism of $B$. subtilis dispersal and highlights a connection 66 between emergence of spores and biofilm disassembly (Fig. 1). Interestingly, B. subtilis grown in 67 variety of commonly used synthetic and complex biofilm media (e.g. MSgg and 2xSGG) does not display typical dispersal. The pellicle remains robust for up to a week at $30^{\circ} \mathrm{C}$, during which time only a minor and very slow decay in the thickness is observed in MSgg grown pellicles. However, 
pellicles that were cultivated at $37^{\circ} \mathrm{C}$ in a modified LBGM medium (lysogeny broth supplemented

71 with glycerol and manganese (20), but containing reduced amount of manganese compared to

72 previous publications) showed a rapid establishment within a day, fragmented structure on the

73 second day, and strong dispersal after 3 days. While removal of manganese prevents biofilm

74 development $(20,21)$, supplementation at lower concentration creates conditions that allows

75 examination of the full pellicle biofilm life cycle in $B$. subtilis, including dispersal. These observations highlight that biofilm dispersal might be more prevalent in the laboratory when slight starvation is encountered, a condition that likely exists for microbes in nature. Interestingly, the number of viable cells remained constant throughout the 3 days (19), suggesting the lack of active lysis or cell death, but rather the presence of passive dispersal in B. subtilis succeeding the previously reported reduced matrix gene expression at later stages of the pellicle development $(12,15)$. Synthetic induction of genes involved in synthesis of the exopolysaccharides throughout the cultivation and therefore prolonged exopolysaccharide production partially prevents biofilm dispersal (19), thus the reduced matrix production only partially explains pellicle biofilm dispersal.

What could facilitate $B$. subtilis cells' dispersal from a biofilm in addition to reduced matrix expression? B. subtilis, when colonizing plant roots under hydroponic conditions, first produces the biofilm matrix followed by robust spore formation (22). Spore are anticipated to survive the

87 harsh conditions in the soil, including predation by protozoans, nematodes, or other microbes 88 (23-25). Therefore, pellicle dispersal could understandably be mediated by release of spores. Nishikawa and Kobayashi (19) demonstrate that the induction of sporulation pathway, which 90 depends on a cascade of sigma factors activating specific gene expression either in the mother cell

$91\left(\sigma^{\mathrm{E}}\right.$, and $\left.\sigma^{\mathrm{K}}\right)$ or in the pre-spore $\left(\sigma^{\mathrm{F}}, \sigma^{\mathrm{G}}\right)$, contributes to dispersal. Indeed, circumventing spore formation by disrupting these sporulation-specific sigma factors, in addition to concomitantly 
synthetically prolonging exopolysaccharide production, prevents pellicle dispersion. Systematic disruption of $\sigma^{\mathrm{k}}$-dependent genes, the last downstream sigma factor within the activation cascade, revealed that spoVFA-spoVFB operon is sufficient to explain biofilm dispersal in $B$. subtilis. The spoVFA-spoVFB operon encodes a dipicolinic acid synthase that creates dipicolinic acid (DPA). DPA after being produced in the mother cells is transported to the forespore compartment where it starts chelating calcium ions contributing to dehydration and mineralization of the spore (26). The direct connection between DPA mediated chelation of calcium, and pellicle dispersal could be verified by addition of calcium to the biofilm medium, which prevented dispersal (19). The impact of calcium on biofilm colony development has been previously observed (27). Consistently, both Nishikawa and Kobayashi (19) and Mhatre et al. (27) could demonstrate that calcium does not impact the expression of matrix genes in established pellicle biofilms and under biofilm inducing conditions, respectively, besides both studies reported larger biofilm colony size in the absence of calcium. The larger colony size observed in the absence of calcium is likely connected to passive surface spreading, termed sliding, as the influence of calcium on colony size was only apparent in the presence of matrix components and surfactin that are all necessary for sliding (27-29). Production of the secondary metabolite surfactin, while not being essential for biofilm development, alters the architecture of biofilm colonies (30). Calcium influences self-assembly of surfactin (31), which might explain a possible impact of calcium on surface tension and therefore biofilm colony size (27). Nevertheless, it remains to resolve the direct connection between calcium level and surfactin functioning in colonies.

Thus, calcium has an important role both in spore maturation and also influences dispersal. Nishikawa and Kobayashi (19) offer a plausible explanation how spore formation indirectly influences biofilm weakening. Besides lower production of the matrix, the onset of spore 
maturation and accompanying DPA production depletes the calcium in the extracellular matrix, resulting in biofilm dispersal (Fig. 1). Calcium seems to impact the biofilm matrix and/or influence regulation of biofilm in numerous bacteria (32-34). It remains to demonstrate whether and how calcium directly interacts with the biofilm matrix in B. subtilis. Nevertheless, the elegant work by Nishikawa and Kobayashi describes an intriguing example of passive dispersal and connects spore formation with it release from the biofilms.

\section{ACKNOWLEDGEMENT}

Biofilm related work in the group of Á.T.K. is supported by a DTU Alliance Strategic Partnership

PhD fellowship. Work in the laboratory of N.R.S.-W. is funded by the Biotechnology and Biological

Science Research Council (BBSRC) (BB/P001335/1 and BB/R012415/1).

\section{REFERENCES}

129 1. Watnick P, Kolter R. 2000. Biofilm, city of microbes. J Bacteriol 182:2675-2679.

130 2. Kovács Át. 2019. Bacillus subtilis. Trends Microbiol 27:724-725.

131 3. Branda SS, González-Pastor JE, Ben-Yehuda S, Losick R, Kolter R. 2001. Fruiting body 132 formation by Bacillus subtilis. Proc Natl Acad Sci U S A 98:11621-11626.

133 4. Mhatre E, Monterrosa RG, Kovács ÁT. 2014. From environmental signals to regulators: 134 Modulation of biofilm development in Gram-positive bacteria. J Basic Microbiol 54:616632.

136 5. Cairns LS, Hobley L, Stanley-Wall NR. 2014. Biofilm formation by Bacillus subtilis: New insights into regulatory strategies and assembly mechanisms. Mol Microbiol 93:587-598.

6. Arnaouteli S, Bamford N, Stanley-Wall NR, Kovács ÁT. 2021. Bacillus subtilis biofilm 
formation and social interactions. Nat Rev Microbiol https://doi.org/10.1038/s41579-02100540-9.

7. Blake C, Christensen MN, Kovacs AT. 2021. Molecular aspects of plant growth promotion and protection by Bacillus subtilis. Mol Plant-Microbe Interact 34:15-25.

8. Vlamakis H, Aguilar C, Losick R, Kolter R. 2008. Control of cell fate by the formation of an architecturally complex bacterial community. Genes Dev 22:945-953.

9. Marlow VL, Cianfanelli FR, Porter M, Cairns LS, Kim Dale J, Stanley-Wall NR. 2014. The prevalence and origin of exoproteaseproducing cells in the Bacillus subtilis biofilm. Microbiol (United Kingdom) 160:56-66.

10. Hölscher T, Bartels B, Lin Y-C, Gallegos-Monterrosa R, Price-Whelan A, Kolter R, Dietrich LEP, Kovács ÁT. 2015. Motility, chemotaxis and aerotaxis contribute to competitiveness during bacterial pellicle biofilm development. J Mol Biol 427:3695-3708.

11. Kobayashi K. 2007. Bacillus subtilis pellicle formation proceeds through genetically defined morphological changes. J Bacteriol 189:4920-4931.

12. Otto SB, Martin M, Schäfer D, Hartmann R, Drescher K, Brix S, Dragoš A, Kovács ÁT. 2020. Privatization of biofilm matrix in structurally heterogeneous biofilms. mSystems 5:e0042520.

13. Martin M, Dragoš A, Hölscher T, Maróti G, Bálint B, Westermann M, Kovács ÁT. 2017. De novo evolved interference competition promotes the spread of biofilm defectors. Nat Commun 8:15127.

14. Špacapan M, Danevčič T, Štefanic P, Porter M, Stanley-Wall NR, Mandic-Mulec I. 2020. The ComX quorum sensing peptide of Bacillus subtilis affects biofilm formation negatively and sporulation positively. Microorganisms 8:1131. 
15. Pisithkul T, Schroeder JW, Trujillo EA, Yeesin P, Stevenson DM, Chaiamarit T, Coon JJ, Wang JD, Amador-Noguez D. 2019. Metabolic remodeling during biofilm development of Bacillus subtilis. MBio 10:e00623-19.

16. Futo M, Opašić L, Koska S, Corak N, Široki T, Ravikumar V, Thorsell A, Lenuzzi M, Kifer D, Domazet-Lošo M, Vlahoviček K, Mijakovic I, Domazet-Lošo T. 2021. Embryo-like features in developing Bacillus subtilis biofilms. Mol Biol Evol 38:31-47.

17. Hobley L, Kim SH, Maezato Y, Wyllie S, Fairlamb AH, Stanley-Wall NR, Michael AJ. 2014. Norspermidine is not a self-produced trigger for biofilm disassembly. Cell 156:844-854.

18. Leiman SA, May JM, Lebar MD, Kahne D, Kolter R, Losick R. 2013. D-Amino acids indirectly inhibit biofilm formation in Bacillus subtilis by interfering with protein synthesis. J Bacteriol 195:5391-5395.

19. Nishikawa M, Kobayashi K. 2021. Calcium prevents biofilm dispersion in Bacillus subtilis. J Bacteriol.

20. Shemesh M, Chaia Y. 2013. A combination of glycerol and manganese promotes biofilm formation in Bacillus subtilis via histidine kinase KinD signaling. J Bacteriol 195:2747-2754.

21. Mhatre E, Troszok A, Gallegos-Monterrosa R, Lindstädt S, Hölscher T, Kuipers OP, Kovács ÁT. 2016. The impact of manganese on biofilm development of Bacillus subtilis. Microbiology $162: 1468-1478$.

22. Charron-Lamoureux V, Beauregard PB. 2019. Arabidopsis thaliana seedlings influence Bacillus subtilis spore formation. Mol Plant-Microbe Interact 32:1188-1195.

23. Laaberki MH, Dworkin J. 2008. Role of spore coat proteins in the resistance of Bacillus subtilis spores to Caenorhabditis elegans predation. J Bacteriol 190:6197-6203.

24. Klobutcher LA, Ragkousi K, Setlow P. 2006. The Bacillus subtilis spore coat provides "eat 
resistance" during phagocytic predation by the protozoan Tetrahymena thermophila. Proc Natl Acad Sci U S A 103:165-170.

25. Seccareccia I, Kovács ÁT, Gallegos-Monterrosa R, Nett M. 2016. Unraveling the predatorprey relationship of Cupriavidus necator and Bacillus subtilis. Microbiol Res 192:231-238.

26. Setlow P. 2006. Spores of Bacillus subtilis: Their resistance to and killing by radiation, heat and chemicals, p. 514-525. In Journal of Applied Microbiology.

27. Mhatre E, Sundaram A, Hölscher T, Mühlstädt M, Bossert J, Kovács ÁT. 2017. Presence of calcium lowers the expansion of Bacillus subtilis colony biofilms. Microorganisms 5:7.

28. Hölscher T, Kovács ÁT. 2017. Sliding on the surface: bacterial spreading without an active motor. Environ Microbiol 19:2537-2545.

29. Grau RR, De Oña P, Kunert M, Leñini C, Gallegos-Monterrosa R, Mhatre E, Vileta D, Donato V, Hölscher T, Boland W, Kuipers OP, Kovács ÁT. 2015. A duo of potassium-responsive histidine kinases govern the multicellular destiny of Bacillus subtilis. MBio 6:e00581-15.

30. Thérien M, Kiesewalter HT, Auria E, Charron-Lamoureux V, Wibowo M, Maróti G, Kovács ÁT, Beauregard PB. 2020. Surfactin production is not essential for pellicle and root-associated biofilm development of Bacillus subtilis. Biofilm 2:100021.

31. Arutchelvi J, Sangeetha J, Philip J, Doble M. 2014. Self-assembly of surfactin in aqueous solution: Role of divalent counterions. Colloids Surfaces B Biointerfaces 116:396-402.

32. Das T, Sehar S, Koop L, Wong YK, Ahmed S, Siddiqui KS, Manefield M. 2014. Influence of calcium in extracellular DNA mediated bacterial aggregation and biofilm formation. PLoS One 9:e91935.

33. Liu X, Zhang K, Liu Y, Zou D, Wang D, Xie Z. 2020. Effects of calcium and signal sensing systems on Azorhizobium caulinodans biofilm formation and host colonization. Front 
Microbiol 11:563367.

209 34. Tischler AH, Lie L, Thompson CM, Visick KL. 2018. Discovery of calcium as a biofilm-

210 promoting signal for Vibrio fischeri reveals new phenotypes and underlying regulatory

211 complexity. J Bacteriol 200:e00016-18.

212

213

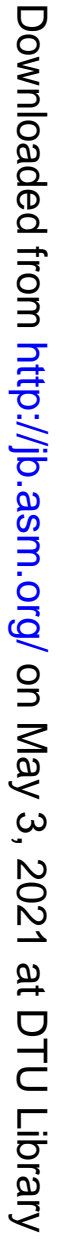


$214 \quad$ Figure 1

215 Schematic representation of the B. subtilis pellicle biofilm life-cycle. After inoculation of 216 planktonic cells, oxygen depletion drives the motile cells to the air-medium interface, where 217 biofilm formation is initiated. At the start, part of the population produces the biofilm matrix. 218 During biofilm maturation, most cells expend energy making the biofilm matrix and calcium is 219 distributed across the biofilm, possibly stabilizing the matrix structure. Before dispersal, matrix 220 production diminishes, and spores are formed that chelate available calcium. Calcium depletion 221 and reduced matrix production allow passive dispersal of $B$. subtilis pellicle biofilms. Figure 222 created with BioRender.com 
